ANATOMY

\section{How to get ahead}

\section{A thorough review of how the human head evolved shows how hominins outpaced apes, finds Henry Gee.}

A lmost everything we know of our world comes through one structure - the head. Our organs of sight, hearing, smell, taste and balance huddle in this crowded tenement, which comprises just $8 \%$ of our body's mass. Meanwhile, down in the basement, air flows in and out; food is swallowed and processed; and sounds emerge - from belches to Beethoven. All this activity is coordinated by the brain, the head's largest and most mysterious organ.

Given this foam of business, it is amazing that we get any peace. That we do is testament to the integration of the head - despite sharing such a small space, all its tenants get on famously. This integration, says Daniel Lieberman in The Evolution of the Human Head, his thorough review of the head's anatomy and development, is key to the powerful ability of the human head to evolve. A small amount of tinkering in one part can lead to a more comprehensive reorganization, as the various sections of the head mould themselves to new circumstances.

The head divides into three parts: the brain and the cranial vault that houses it; the cranial base on which the brain sits; and the face, hafted to the front of both. Each influences the others, explains Lieberman, a professor of human evolutionary biology at Harvard University in Cambridge, Massachusetts. Together the three parts determine the look of modern humans compared with other apes. A larger brain needs a more flexed cranial base to support it, thus shortening the face, which is retracted under the braincase. So our heads appear less extended than those of our closest animal relatives.

A shorter pharyngeal cavity relative to the neck gives us a system of tubes that produces more intelligible speech sounds than a longer one could. Our short, round tongue decouples the epiglottis from the soft palate, giving more access for odorants to nasal epithelia. A shorter face means a smaller jaw, all the better for chewing cooked foods, thus getting more energy per morsel, necessary for maintaining a large

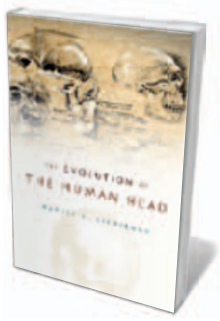

The Evolution of the Human Head DANIEL E. LIEBERMAN Belknap Press: 2011. 768 pp. $\$ 39.95$ feedback loop contributes to the continuing success of Homo sapiens.

Lieberman does well to steer a course away from the blurry and disputed details of hominin lineages. Instead he focuses on the basics of how the head develops. He sets out the elegant certainties of biomechanics: how the strains of chewing influence bone deposition and resorption; how the mechanics of jaw shape interact with the cranium and the associated tendons and musculature to integrate the head's components; how the shape of the nose promotes turbulent airflow and thus efficient detection of odorants, and moderation of heat loss and water resorption; and how the dimensions of the ear canal attenuate some frequencies while amplifying others.

Lieberman's thoroughness especially enriches the final quarter of the book - a tour of human evolution in terms of the detailed changes wrought on head anatomy
DNATURE.COM

For a review of Neil Shubin's Your Inner

Fish:

go.nature.com/yb2sk8 over the past few million years. Climate change was to blame: the drying, cooling climate forced forest apes to either retreat farther into the trees or adopt more marginal lifestyles.

A bipedal life, however, forced certain compromises. The lack of lengthy canines in early hominins might be less to do with sexual selection than the imposition of a shorter face (with less room for long teeth) on a head seeking balance atop an upright carriage. Some early hominins became better at subsistence on the marginal fare of roots and seeds, evolving immense teeth and powerful, crushing jaws. Others, the descendants of which became Homo, found that although nutritious fruits were scarce on the savannah, nutritious ungulates were common - but they needed to be caught.

The hunting imperative led to a suite of features suggesting that humans, uniquely among primates, became excellent long-distance runners. No chimpanzee, for example, could attempt a marathon across the Sahara Desert. Yet human athletes do this, and survive. Running imposes many constraints and demands on the head of a biped, connected with stabilization and protection from shock, which are seen in the anatomy of humans but not in apes. One such feature, the nuchal ligament that links the back of the skull to the neck, finds parallels in other chasers-of-prey such as dogs.

Most pursuit predators and scavengers work at dusk, dawn or at night. Even before the evolution of Englishmen, early humans found that the midday Sun offered a vacant niche. Because humans can maintain a pace that exceeds the walking speed of many quadrupeds, even in the heat of the day, the quarry is forced to stand its ground or run and risk collapsing from hyperthermia. Bushmen adopt such a hunting strategy to this day. Its use by early Homo could have promoted the many adaptations seen for long-distance running, as well as the thoroughgoing changes in the structure of the head and face that set humans apart from all other apes.

By rooting his study in the basics of tissue mechanics and functional morphology, Lieberman does the spadework to which all such studies aspire but few achieve - and makes that task seem elegant and effortless.

Henry Gee is a senior editor at Nature. e-mail:h.gee@nature.com

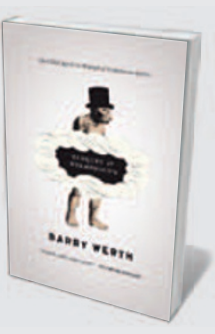

Banquet at Delmonico's: The Gilded Age and the Triumph of Evolution in America Barry Werth (Univ. Chicago Press, 2011; \$19) Philosopher Herbert Spencer took Charles Darwin's ideas to the United States in 1882. Barry Werth focuses on the influential diners at a banquet held in Spencer's honour, describing how they used evolutionary ideas in an attempt to improve society.
Mothers and Others: The Evolutionary Origin of Mutual Understanding Sarah Blaffer Hrdy (Belknap Press, 2011; \$19.95) In her provocative book, anthropologist Sarah Blaffer Hrdy argues that because human infants are too expensive to be raised by mothers alone, both parents must invest heavily in social skills to bargain with other group members for resources. 